\title{
Willingness to change car use under a tradable driving credits scheme: A comparison between Beijing and the Netherlands
}

\author{
Nico Dogterom (Corresponding author) \\ Utrecht University \\ n.j.dogterom@uu.nl
}

\section{Meng Xu}
Beijing Jiaotong University
mengxu@bjtu.edu.cn

\author{
Yue Bao \\ Beijing Jiaotong University \\ yuebao@bjtu.edu.cn
}

Dick Ettema

Utrecht University

d.f.ettema@uu.nl

\begin{abstract}
Recent years have seen a surge of interest in the concept of tradable driving credits (TDC) as an alternative to road pricing and driving restriction measures. However, empirical research into drivers' responses to a TDC measure is limited and even lacking for the Chinese context where the concept of TDC has attracted considerable attention. This paper reports the results of a survey that was the first to investigate drivers' willingness to change car use under a hypothetical distance-based TDC measure in China (Beijing) and aimed to compare these results with the results of a comparative Dutch survey. We observed that willingness to change was considerably higher in Beijing than in the Netherlands and that a substantial share of Beijing car owners indicated an increase in car use. In both contexts, higher education and higher car use intensity had a positive effect on the willingness to change, whereas higher income had a negative effect. We found mixed results for household size, respondents' car attitudes, and TDC scenario characteristics.
\end{abstract}

Keywords: tradable driving credits, car use, travel demand management, willingness to change, Beijing, the Netherlands

\section{Article history:}

Received: October 31, 2016

Received in revised form: August 16, 2017

Accepted: January 5, 2018

Available online: July 9, 2018

\section{Introduction}

Although many cities around the globe are confronted with the problems of congestion and pollution that are posed by the growing road transport sector, in China, these challenges have manifested themselves at an unprecedented scale. In particular, Chinese megacities, which are the focal points of China's fast economic growth and urbanization, rank among the most congested and polluted cities in the world and have shown no indications of a projected lowering of car use aspirations among its

Copyright 2018 Nico Dogterom, Yue Bao, Meng Xu \& Dick Ettema

http://dx.doi.org/10.5198/jtlu.2018.1039

ISSN: 1938-7849 | Licensed under the Creative Commons Attribution - Noncommercial License 4.0

The Journal of Transport and Land Use is the official journal of the World Society for Transport and Land Use (WSTLUR) and is published and sponsored by the University of Minnesota Center for Transportation Studies. This paper is also published with additional sponsorship from WSTLUR. 
citizens (Wang \& Liu, 2015; Ng, Schipper, \& Chen, 2010). In response, cities such as Shanghai and Beijing have implemented a series of travel demand management measures to address excessive car use. Already in the 1990s, the Shanghai authorities adopted a program by which it issued only a limited monthly number of license plates through an auction to limit the growth of the vehicle population. Beijing started a similar license plate scheme in 2012; however, it chose to issue new license plates by a lottery. In addition, Beijing further rationed car use by implementing a driving restriction measure that does not allow cars to drive on a certain day of the week, based on the last digit of the license plate (Xu, Grant-Muller, Huang, \& Gao, 2015; Hao, Wang, \& Ouyang, 2011).

Although these measures have slowed new vehicle purchases and reduced traffic congestion and air pollution to some extent (Sun, Zheng, \& Wang, 2014; Hao et al., 2011) researchers commonly agree that these measures - that are appealing to regulators because of their simplicity, quick and visible shortterm effects, and implementation at relative low costs - are not sustainable and effective in the long run and have given rise to significant negative side effects. These restrictions do not fundamentally target the intensity of car use (vehicle kilometers travelled, VKT) and therefore can lead to increased car use by those allowed to drive. For Beijing, Yang, Liu, Qin, and Liu (2014) projected only a 1\% decrease in annual fuel consumption by 2020, whereas they expected the total number of vehicles to decrease by $11 \%$ with the license plate lottery scheme in place. Further, Beijing's driving restriction has led to compensating responses, such as the temporal substitution of car use, second car purchases, and noncompliance behavior (Wang, Xu, \& Qin, 2014). Shanghai's license plate auction scheme, which can make the right to access the roads as expensive as $¥ 100,000$ (almost $€ 15,000$ ), and has resulted in only the wealthy being able to drive, has been heavily criticized for its equity implications (Chen \& Zhao, 2013). Nie (2017) laid out a more fundamental criticism of license plate restrictions by mathematically showing that it can never be a first-best nor a guaranteed second-best solution, as it cannot improve the system costs in any configuration.

Making access to roads "tradable" can offer a solution to these problems, as noted by Nie (2017) (see also Verhoef, Nijkamp, \& Rietveld, 1997; Goddard, 1997; Yang \& Wang, 2011). Applying a tradable credits approach to managing personal car use, which would lead to situations in which drivers could trade their individual share of a total quantity of road access, could address the welfare loss problems that are associated with the above-discussed measures. Simultaneously, it could provide regulators with more direct control of VKT when, for example, the total quantity is set in units of distance or fuel consumption. Under a tradable credits measure, an economic price that is determined by actual supply and demand would be attached to car use, which according to transport economists is crucial to obtain an efficient allocation of scarce road space. At the same time, major objections to conventional road pricing could be addressed by the scheme through the allocation of a minimum amount of "free" credits - through which authorities could also pursue certain distributional outcomes — and by providing drivers an opportunity to realize financial benefit by selling excess credits.

Recent years have seen a surge of interest in the concept of tradable credits in the transport domain, which has led to many theoretical explorations (see for reviews Grant-Muller \& Xu, 2014; Fan \& Jiang, 2013). However, to come to a more comprehensive evaluation of tradable credit-based measures, it is critical to investigate the responses of those who as car owners will be affected by the measure at the micro-level. However, empirical research that seeks to anticipate drivers' responses to tradable creditbased measures is scarce and even missing for the Chinese context, although China is well-represented in theoretical discussions on the concept. The available empirical research, which only relies on data from the USA, the UK, France and the Netherlands, suggests that these measure can mobilize shares of car users to change their behavior, realize car use change magnitudes, and achieve support levels that are comparable or even larger than more or less equivalent conventional road pricing schemes (see for a review Dogterom, Ettema, \& Dijst, 2017). 
The aim of this paper is to contribute to this small body of literature on the behavioral impacts of tradable driving credits (TDC) schemes, specifically by being the first to present results from a Chinese context. It investigates data that were collected by surveys that were conducted in Beijing (China) and the Netherlands, by which car owners' willingness to change and type of behavioral change in response to distance-based TDC scenarios were examined. By relating the Chinese data to the Dutch data, we are able to directly compare car use change behavior and to investigate the extent to which general patterns and preferences and important differences between an Asian and European context can be found. In doing so, we bear in mind the important geographical, socio-economic and cultural differences that exist between both contexts.

In the next section, we will provide background information about the existing studies on TDC. Then, we will outline our data collection procedure and samples, after which we will present the results. We will end with a conclusion and a discussion.

\section{Background}

The concept of tradable credits originates from the field of environmental economics. Since Dales (1968) proposed marketable pollution rights as a new policy to tackle water pollution, the concept has found numerous applications that attempt to mitigate environmental problems (Tietenberg, 2003). Later, Verhoef et al. (1997), Goddard (1997), Viegas (2001), Raux (2004), Kockelman and Kalmanje (2005), and Buitelaar, van der Heijden, and Argiolu (2007) have begun to explore the potential of tradable credits in the domain of urban road transport. Given the ongoing growth of excessive car use demand in many urban contexts and the massive unpopularity of traditional pricing-based measures, together with the present availability of advanced and ubiquitous ICT technologies, the tradable credit approach for managing car mobility has been more vigorously researched in recent years. Yang and Wang's study (2011), which theoretically demonstrated that a tradable credits scheme leads to the most desirable network traffic flows in a revenue-neutral way under an appropriate credits allocation and correct link-specific charges, led to many other studies that analyze traffic patterns and credit price behavior under different user and market equilibrium assumptions (e.g., Wu, Yin, Lawphongpanich, \& Yang, 2012; Wang, Yang, Zhu, \& Li, 2012; Ye \& Yang, 2013; Nie \& Yin, 2013; Xiao, Qian, \& Zhang, 2013; Bao, Gao, Xu, \& Yang, 2014; Wang, Gao, Xu, \& Sun, 2014).

The focus of these studies therefore has largely been on macroscopic analysis. Based on this observation, Xu and Grant-Muller (2016a, 2016b) presented a microscopic simulation analysis in which they examined TDC effects on vehicle distance travelled and mode choice based on existing travel data for the cities of Beijing and London. They showed that TDC could effectively affect travelers' mode choice and could be a viable alternative to normal road pricing with regard to car use intensity. Although this disaggregate simulation approach using existing travel data is already an important step in connecting theoretical models to real-world travel patterns, which is inevitably needed to obtain predictions of TDC's effects, these studies still rely on very basic assumptions that do not differentiate between travelers' space-time context and socio-economic status.

Empirical research that has focused on the individual level is very limited. However, such research can provide insight into anticipated travelers' responses to TDC in a more realistic way and can, through statistical analysis, differentiate between groups in regard to behavioral responses. In their proposal for a congestion-based congestion pricing scheme, Kockelman and Kalmanje (2005) surveyed respondents from the Austin area (TX, USA) about their likely reactions to such a scheme. They found that willingness to change current driving behavior decreased with age, income and vehicle ownership when the respondents were asked how many days they would modify peak-based trips to save credits. In the UK, Zanni, Bristow, and Wardman (2013) investigated behavioral adaptations in response to a tradable 
credit scheme that, in addition to personal travel, covered all other personal carbon-producing behavior. Their results showed that people with higher incomes, who are gainfully employed and live in larger households are more likely to change their current carbon-producing behavior. Raux, Croissant, and Pons (2015), comparing changes in travel behavior in response to both a tradable credit scheme and an equivalent tax in France, found socio-economic characteristics to only weakly affect car use change, only finding a significant negative effect on willingness to adapt car use for older respondents in the case of a tradable credit scheme.

Dogterom, Ettema, and Dijst (2018) designed a stated adaptation experiment in which Dutch frequent car commuters could make modifications in their one-week car travel pattern that was recorded prior to the experiment. The respondents were presented with two TDC scenarios, in which the allocated credits represented a $17.5 \%$ and a $32.2 \%$ reduction in the total VKT of the sample in a first and a second scenario, respectively. The participants received equal-sized credit budgets, meaning that the credit shortage (loss) or surplus (gain) in the base situation was proportional to their individual VKT. After controlling for the size of financial loss and gain, the results indicate that willingness to make travel adaptations to change the financial outcome increased with the number of children who live in the household and decreased with living in a non-urbanized area. Males were more willing to change their car use in the first scenario, meaning that the gender difference disappeared under a stricter budget; however, at the same time, under this narrower budget, the respondents with a middle income were more prepared than the other income groups to make adaptations in their car use.

Only Zanni, Bristow, and Wardman (2013) and Dogterom et al. (2018) were able to model behavioral change as a function of the size of the financial gain or loss that is faced by the respondents, as they used an experimental design that was configured to resemble a scheme with an equal-per-capita credit allocation that was applied to drivers with heterogeneous travel demand. Both studies found that facing a loss had a larger impact on willingness to change behavior and that this willingness increased with larger losses and decreased with larger gains.

This paper extends to the studies that are discussed above in that it is the first that presents results from a Chinese context, especially from the city of Beijing, which is a context where the problems of excessive car use are particularly pressing and the need for viable travel demand management measures is highly relevant. It is somewhat surprising that the behavioral effects of TDC have not been investigated in China, while a large share of the theoretical studies on TDC has been produced in that country. Additionally, with regard to the road pricing literature in general, the individual-based empirical research is very limited in China as compared to western counties. Further, presenting results from China together with results of a similar study from the Netherlands is an important contribution, as this enables a direct comparison of the Chinese findings with findings from a western context. Finally, with regard to the Dutch context, this paper extends the study of Dogterom et al. (2018) in that it reveals the preferences of the broader group of car owners instead of only the sub-group of frequent car commuters. This paper seeks to determine whether the influencing factors that are identified for more intense car users also play a role for the category of drivers that is a more representative sample of the car-owner population, including non-workers. There may be a greater likelihood of car use change in this group, which on average might be less car-dependent and less forced to drive during peak hours. The data that we present for Beijing will be explorative in essence, as findings cannot be studied in an already-available literature on drivers' responses to pricing initiatives in that context.

At the same time, we believe that several factors are relevant to take into account when interpreting data from both Beijing and the Netherlands in a comparative analysis. First, there are important geographical and socio-economic factors, as the Dutch data are collected through a national sample, whereas the Chinese data are confined to the city of Beijing alone. Beijing is a megacity that, having more inhabitants than the Netherlands as a whole, considerably differs from the Dutch research context in the 
structure of the built-up area, the profile of the population and the scale of traffic-related problems. Each location in Beijing is relatively easy to reach by public transport and its highly dense structure provides many feasible alternative locations for the amenities that are used by its inhabitants, which is different for the less-urbanized areas of the Netherlands. However, in terms of sample profiles we expect that both samples will be more similar than one might initially expect, as the population of car owners in Beijing largely consists of a relatively homogeneous middle class group, which shares more or less western levels of education, income and activity participation. At the same time, there is an important difference in car culture between both contexts. More than in the Netherlands, in Chinese cities the use of travel modes is imbued with psychosocial meaning, and car ownership and use have a strong symbolic appeal for urban residents, marking their entry to the new rising middle class and being a sign of affluence that is eagerly displayed (Williams \& Arkaraprasertkul, 2016; Yang et al., 2014). This phenomenon may negatively affect drivers' preparedness to seek alternatives for their car use, even in conditions under which drivers would face increasing operational costs. In the context of the present driving restrictions in Beijing, the implementation of a TDC scheme, in which people can in fact buy road access according to their needs and desires, could potentially mean that higher income groups and those who find their present travel demand highly suppressed by the existing measures would increase their car use under a TDC scheme. Therefore, to analyze the effects of the psychosocial meaning of car use, we included information about the respondents' car attachment in the analysis.

\section{Data collection}

\subsection{1 Survey design}

The data were mainly collected through an online survey. Only in Beijing, 10\% of the respondents were approached on the streets with a pencil-and-paper version of the survey. The data collection occurred in June (the Netherlands) and July (Beijing) 2016. The respondents were recruited through a panel in both countries. The panel sent an invitation to panel members with a short description of the research. Car ownership was the only criterion for being able to participate in the research. In the Netherlands, the respondents were recruited from all over the country.

In the introduction of the measure, it was stated that the experiment was an academic investigation of the effects of TDC as an alternative measure to combat congestion and that there were no plans for actual implementation. It was communicated that each driver would be allocated a personal budget that contained credits (one credit represented one kilometer) that would allow the driver to drive a certain number of kilometers without additional costs. The driver would be required to buy additional credits when she exceeded her personal credit budget, and she could sell the credits that were left over when she drove less than the amount of credits in the budget. It was communicated that respondents would need credits for all kilometers driven, irrespective of time and location. Based on the description and the functioning of the experiment, the respondents had a clear idea of the functioning and implications of a hypothetical TDC scheme in their personal situation.

Although both approaches to the data collection were similar, there were some differences in the design and procedure of the survey, thus we discuss the details of the data collection separately for the Netherlands and Beijing.

\subsubsection{Beijing}

First, the respondents were asked to report their car use during the previous 7 days. They were asked to indicate the number of activities and total VKT for 3 different activity groups: "work and education," 
"personal maintenance" and "leisure." With regard to VKT, the respondents could choose one of the following classes: "less than $50 \mathrm{~km}$ " "50-100 km," "100-150 km," "150-200 km" and "more than 200 $\mathrm{km}$." To obtain a rough estimation of the respondents' total VKT, the middle values of these categories were summed ( $225 \mathrm{~km}$ for the "more than $200 \mathrm{~km}$ " category). The respondents were presented with two TDC scenarios. The respondents faced both a credits shortage of 50 credits and a credits surplus of 50 credits. Three different credit values in Chinese Yuan were set (0.5, 0.8 and 1.0), which were randomly assigned to the respondents. The respondents were asked to imagine that their reported car travel was their planned car travel for the upcoming week, for which they had a certain number of credits available. The respondents could indicate whether they wanted to increase or decrease their VKT for the three separate activity groups if the presented scenarios were applicable.

\subsubsection{Netherlands}

The Dutch survey was slightly more detailed, and it was dynamic in the sense that the amount of available credits was a function of the drivers' reported car use. Dutch respondents were asked to indicate the number of activities performed and the total kilometers driven for 11 activity categories, which were classified into 4 overarching activity groups: "work and education," "personal maintenance," "leisure," and "other" (including picking up and dropping off people and objects). The total kilometers driven could be selected from a list of 19 predefined categories.

In contrast to the Beijing survey, the Dutch respondents faced either a credit shortage or a surplus in the second part of the survey. In these scenarios, the number of available credits was a percentage (15\% or $30 \%)$ of their reported VKT. One of the four scenarios was randomly assigned to the respondents, together with one of the three credit values in Euros $(0.10,0.15$ or 0.20$)$. The respondents were asked whether they would make changes in their VKT in the four separate activity groups if the presented TDC scenario with the total financial gain or loss in a no-change situation were applicable. The respondents could change their VKT by selecting either an increase or reduction percentage from a list (rounded to tens).

Both surveys ended with a questionnaire on the respondents' characteristics and their opinions of personal car use and the TDC measure. Three items on car use attachment are included in the analysis of this paper: instrumental (the extent to which a person feels the car is needed in daily life), symbolic (the extent to which the car as an object is meaningful for the person) and affective car attachment (the extent to which a person derives pleasure from using the car) (Steg, 2005). Table 1 presents more information on the operationalization of these items.

\subsection{Sample}

After data preparation, the Dutch sample included 474 respondents, and the Beijing sample included 660 respondents. The socio-demographic characteristics, using the categories that are included in the models, are presented in Table 1, together with information about the respondents' VKT and scores on the car attachment items. For the Dutch sample we have additional information on the characteristics age, relational status, work of both the respondent and his or her partner, and the level of urbanity of the residence municipality, which are unavailable for the Beijing sample. Further, with regard to income, only the Dutch survey included the option "Would rather not say." Whereas in the Netherlands both relational status and the presence of children were asked, in Beijing the household composition was only measured in terms of household size. We regard the attributes "presence of children" and "household size larger than 2" as being more or less comparable, as households in China are largely based on the nuclear family, although a third person could also be another relative instead of a child in the Chinese context. 
Table 1: Sample composition and description of explanatory variables.

\begin{tabular}{|c|c|c|c|c|}
\hline & Beijing $(\mathrm{N}=660)$ & & Netherlands $(\mathrm{N}=474)$ & \\
\hline Characteristics & Operationalization & $\%$ & Operationalization & $\%$ \\
\hline \multicolumn{5}{|l|}{ Socio-demographics } \\
\hline Gender & Male & 48.9 & Male & 49.8 \\
\hline $\begin{array}{l}\text { Disposable household income } \\
\text { per month }\end{array}$ & $>¥ 6,000$ & 54.2 & $\begin{array}{c}>€ 2,500 \\
\text { (no income stated) }\end{array}$ & $\begin{array}{c}39.7 \\
(19.8)\end{array}$ \\
\hline Education & University & 77.9 & $\begin{array}{l}\text { Higher professional educa- } \\
\text { tion and University }\end{array}$ & 38.4 \\
\hline Household & More than 2 persons & 80.5 & Presence of child(ren) & 62.5 \\
\hline Car ownership of household & More than $1 \mathrm{car}$ & 8.9 & More than $1 \mathrm{car}$ & 31.7 \\
\hline Age & $\mathrm{n} / \mathrm{a}$ & $\mathrm{n} / \mathrm{a}$ & Age is $>45$ & 56.3 \\
\hline Relational status & $\mathrm{n} / \mathrm{a}$ & $\mathrm{n} / \mathrm{a}$ & Couple & 74.5 \\
\hline Work & $\mathrm{n} / \mathrm{a}$ & $\mathrm{n} / \mathrm{a}$ & Paid work & 61.8 \\
\hline Work partner & $\mathrm{n} / \mathrm{a}$ & $\mathrm{n} / \mathrm{a}$ & Partner has paid work & 58.9 \\
\hline Urbanity & $\mathrm{n} / \mathrm{a}$ & $\mathrm{n} / \mathrm{a}$ & $\begin{array}{c}\text { Residence municipality has } \\
\text { urbanity level } 1-3 \text { (1= very } \\
\text { strongly urbanised; } 5= \\
\text { non-urbanised) }\end{array}$ & 66.5 \\
\hline VKT & & kilometres & & kilometres \\
\hline Average VKT & & 197.8 & & 339.4 \\
\hline \multirow[t]{3}{*}{ VKT categories } & $<100 \mathrm{~km}$ & 30.3 & $<200 \mathrm{~km}$ & 37.8 \\
\hline & $100-200 \mathrm{~km}$ & 30.3 & $200-400 \mathrm{~km}$ & 28.9 \\
\hline & $>200 \mathrm{~km}$ & 39.4 & $>400 \mathrm{~km}$ & 33.3 \\
\hline Car attachment $^{1}$ & & mean (s.d.) & & mean (s.d.) \\
\hline Instrumental car use & $\begin{array}{l}\text { 'How easy could you } \\
\text { use other transport } \\
\text { modes than the car?' }\end{array}$ & $\begin{array}{c}3.69 \\
(1.73)\end{array}$ & $\begin{array}{l}\text { 'I do not have any alterna- } \\
\text { tives for my car use.'3 }\end{array}$ & $\begin{array}{c}4.22 \\
(1.85)\end{array}$ \\
\hline Symbolic car use & $\begin{array}{l}\text { 'Do you think your } \\
\text { car provides you } \\
\text { status and prestige?'3 }\end{array}$ & $\begin{array}{c}4.10 \\
(1.67)\end{array}$ & $\begin{array}{c}\text { 'My car provides me status } \\
\text { and prestige.' }\end{array}$ & $\begin{array}{c}2.58 \\
(1.50)\end{array}$ \\
\hline Affective car use & $\begin{array}{c}\text { 'Do you think } \\
\text { driving gives you } \\
\text { pleasure?'3 }\end{array}$ & $\begin{array}{c}4.65 \\
(1.53)\end{array}$ & $\begin{array}{l}\text { 'Driving gives me } \\
\text { pleasure.' }\end{array}$ & $\begin{array}{c}4.63 \\
(1.55)\end{array}$ \\
\hline
\end{tabular}

${ }^{1}$ Although the Beijing and the Dutch survey used the same car attachment items, the formulation altered somewhat during the translation process. The presented formulation follows the original formulation as closely as possible.

${ }^{2}$ Measured on a 7 point scale: $1=$ very easy, $7=$ not possible

${ }^{3}$ Measured on a 7 point scale: 1 = fully disagree, 7 = fully agree

One of the most remarkable differences in sample composition is the large share of respondents with a university degree in the Beijing sample. This can be explained by the fact that car ownership in Beijing is largely confined to the middle class and elites, who are, on average, highly educated in the capital of China, which is the seat of many important (inter)national institutes and companies. Another observation is that the VKT per respondent is generally lower in Beijing, which is not surprising given the megacity structure of Beijing and the polycentric structure of the Netherlands. Because the respondents' VKT could only be roughly estimated and because of the differences in the estimation process in both contexts, we enter VKT as a categorical variable, each group including approximately $30 \%$ of the 
sample, rather than as a continuous factor in the models.

As expected, Beijing car owners have substantially higher scores on symbolic car use and are generally more able to replace their car use with other transport modes. The scores on affective car use are very similar in both contexts.

\section{$4 \quad$ Results}

\subsection{Descriptive analysis}

This section discusses some general descriptive results for Beijing and the Netherlands. After providing the results for each context separately, the findings will be brought together in a synthesis.

\subsubsection{Beijing}

Figure 1 presents the percentages of the respondents who are willing to change their reported car use with 50 credits less or 50 credits more than they needed. Approximately $60 \%$ of the respondents indicated a change, both in the case of a credit shortage and a credit surplus. At the same time, the figure presents the shares of type of change: a reduction or an increase in car use. Of those who would change their car use, $20.5 \%$ indicates an increase in kilometers in the credit shortage scenario, while $38.2 \%$ do so in the credit surplus scenario. An increase in car use in a situation of credit surplus is understandable: drivers may wish to fully use their given credit budget. However, the finding that one-fifth of the "changers" report an increase in the case of a credit shortage is somewhat surprising, as this behavior would imply an increase in operational driving costs in addition to the costs that they already would have to pay in a situation without change. These respondents possibly expect that, considering the current practice under the Beijing driving restrictions, TDC would provide them with the freedom to realize their true travel demand. In addition, people may expect better traffic conditions under the TDC measure as it would set an absolute cap on VKT. For the respondents who state a car use increase, the monetary costs that are involved with driving more under TDC could outweigh the costs of suppressed travel under the current travel restriction and conditions. Figure 2 and 3 differentiate between three different activity categories when it comes to willingness to change car use in the shortage and surplus scenarios, respectively.

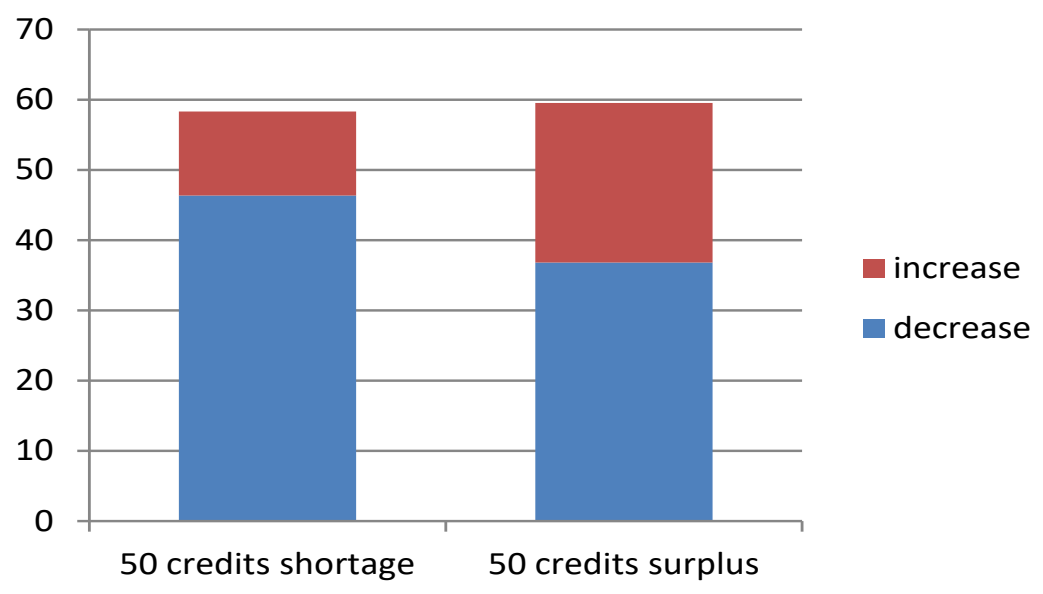

Figure 1: Percentages of respondents willing to change car use in Beijing, under two different TDC scenarios 


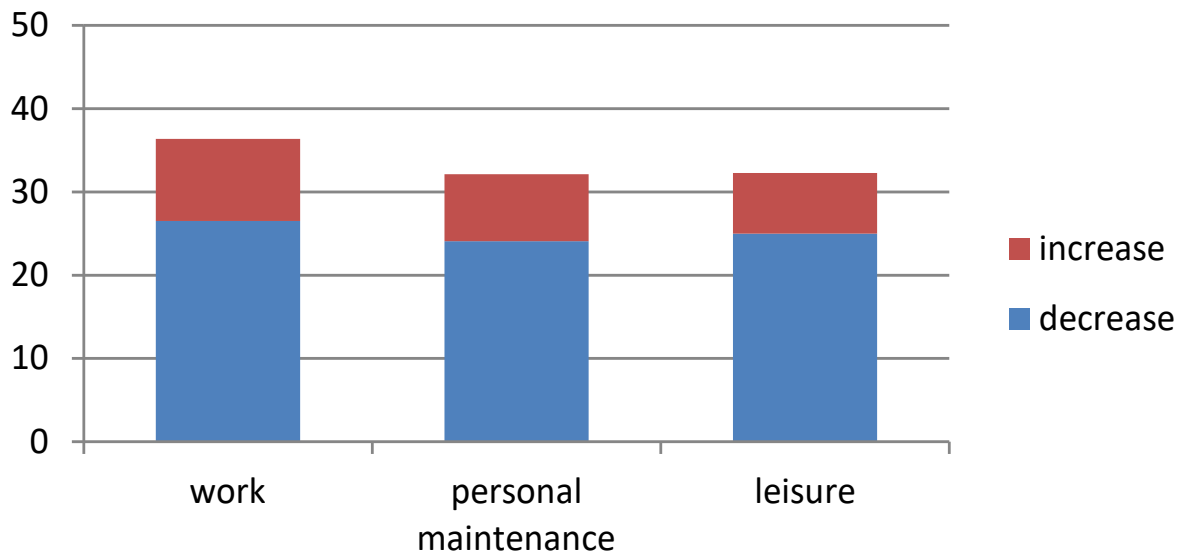

Figure 2: Percentages of respondents willing to change car use in Beijing in different activity categories, under a 50 credits shortage scenario

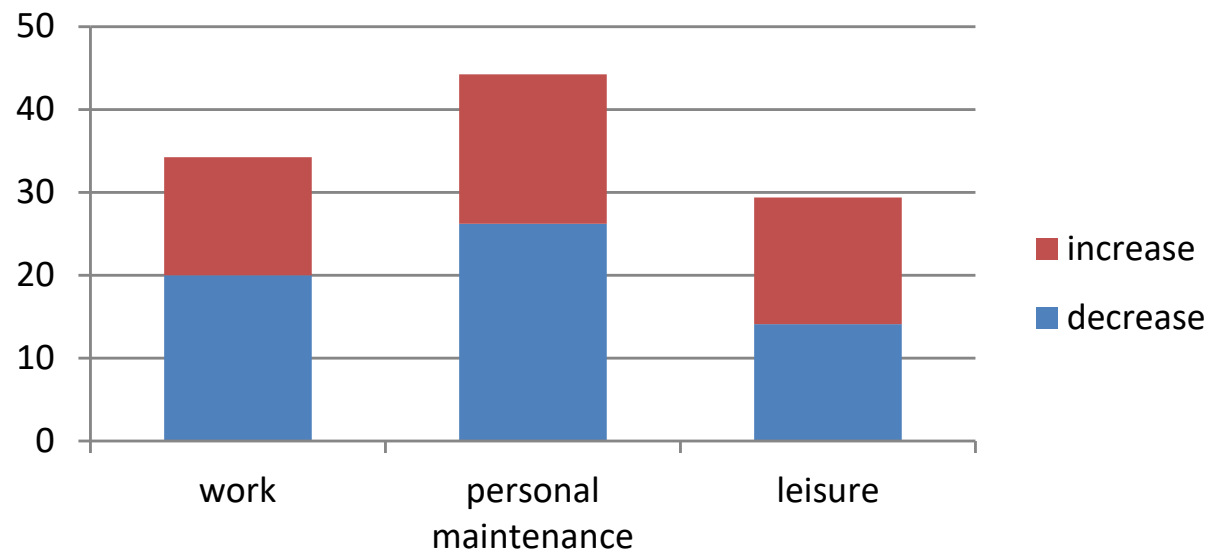

Figure 3: Percentages of respondents willing to change car use in Beijing in different activity categories, under a 50 credits surplus scenario

\subsubsection{The Netherlands}

Figure 4 shows the percentages of the respondents who are willing to make adaptations in their car use for the four different scenarios. There is a sharp difference between the "shortage" and the "surplus" scenarios, with the willingness to change being twice as great for those who would face a loss compared to those who would face a gain. Only very few Dutch drivers indicated a willingness to increase car kilometers: only 8 out of the 101 respondents who indicated a change in car use (therefore, Figure 4 does not distinguish between a decrease and increase of VKT).

Figure 5 provides the percentages of the respondents who realize car use changes in the four different activity categories separately. For the entire sample, work and educational activities are changed the least, followed by the activities in the "personal maintenance," "leisure" and "other" category, although the differences in shares are only minor as the change rates range between $9 \%$ and $15 \%$. When we consider the willingness to change rates distinguished according to scenario type, these patterns are more 
diverse across the scenarios. Overall, the rates show the same pattern as is shown in Figure 4, with the change rates in the "surplus" scenarios being approximately half of those in the "shortage" scenarios. One other more general observation is that the respondents in the "surplus" scenarios show a relative preference for realizing changes in the "other" category.

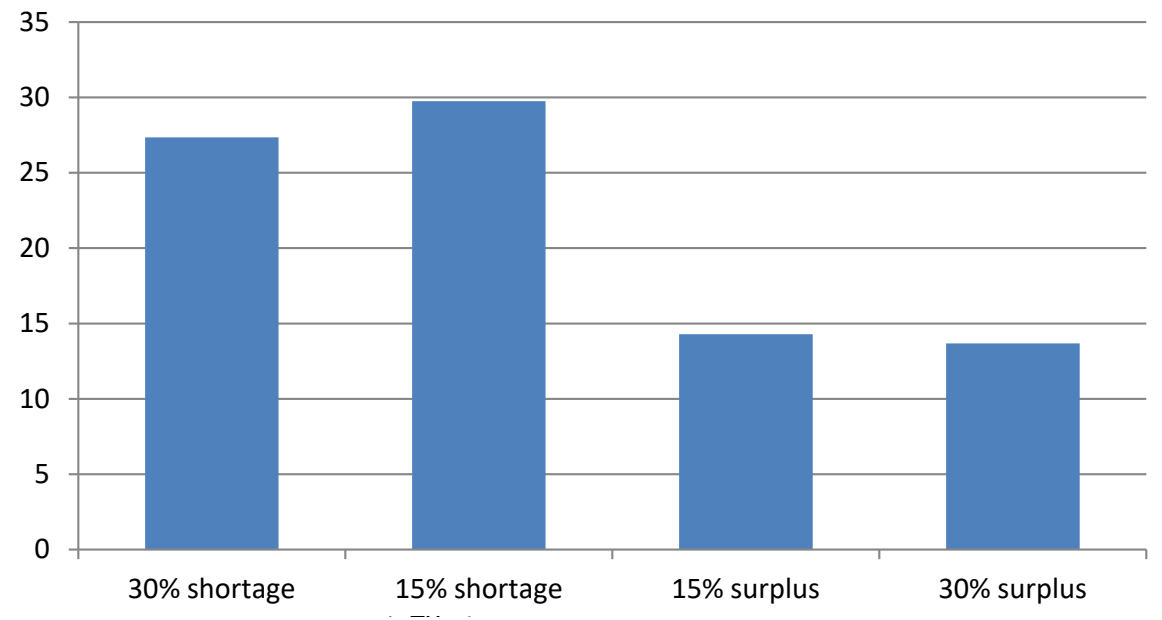

Figure 4: Percentages of respondents willing to change car use in the Netherlands, under four different TDC scenarios

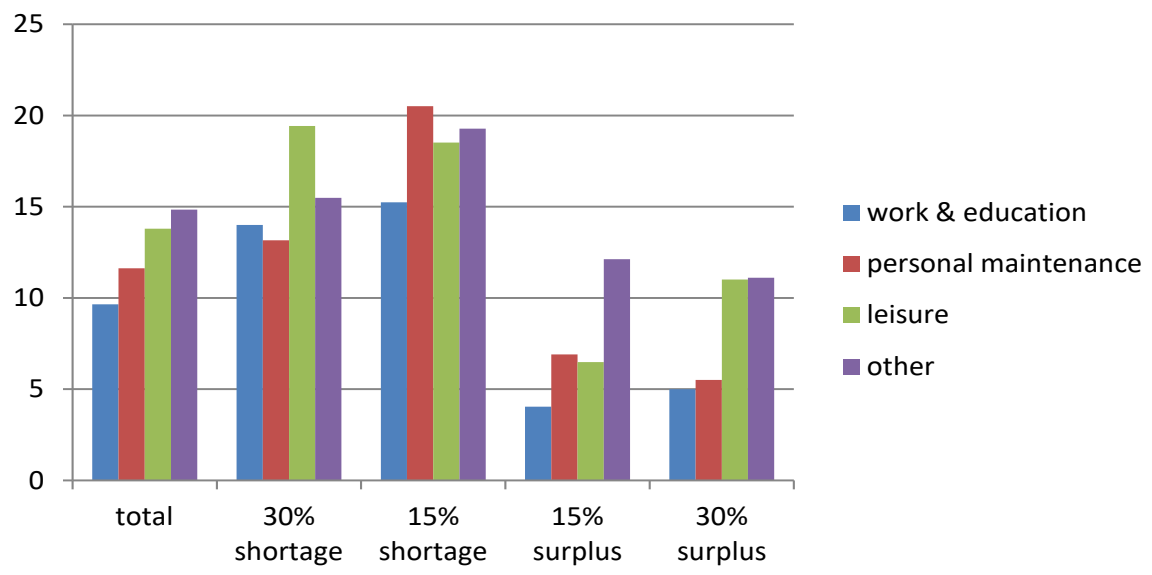

Figure 5: Percentages of respondents willing to change car use in the Netherlands for different activity categories, under four different TDC scenarios

\subsubsection{Synthesis Beijing - The Netherlands}

When comparing the willingness to change rates for Beijing and the Netherlands some general conclusions can be drawn. First, the Beijing sample reports a higher willingness to change (approximately $60 \%$ ) than the Dutch sample (approximately 30\% for the scenarios with the highest willingness to change). Second, a remarkable observation is that the clear contrast in willingness to change between the "shortage" and "surplus" scenarios that is found for the Netherlands is not present in the Chinese case. Third, when we differentiate between reducing car use and increasing car use as two different responses, however, the Beijing car owners also show a higher preparedness to change car use in the case of a credit shortage. Still, the willingness to decrease car use is twice as great in Beijing compared to 
the Netherlands in a surplus situation. In this case, the city environment in which car use can be easily replaced by other forms of travel or activity participation could explain the higher rates of willingness to change in the Beijing context. Fourth, however, a considerable share of the Beijing car owners' change in car use concerns an increase in car use, even in the case of a credit shortage, whereas in the Netherlands, only a few individuals indicated a willingness to drive more kilometers under the TDC. As noted above, this preference could be explained by the current traffic restriction and conditions in Beijing. Current drivers might see their real travel demand suppressed by the one-day-no-driving restriction and the severe traffic jams, and they may expect to travel more by car if they were allowed to drive without formal restrictions and if they could be assured of improved travel times under an absolute VKT cap, regardless of the extra monetary costs involved. The Dutch car owners might already to a large extent be able to realize their true travel demand under the current conditions.

\subsection{Statistical analysis}

In this section, we present logistic regression models that have been estimated to determine the extent to which willingness to change car use is influenced by personal and TDC scenario characteristics. These characteristics include the respondents' socio-demographic characteristics, kilometers travelled and car use attitudes that are outlined in Table 1 as well as scenario attributes (price level, credit shortage/surplus, size of budget).

Table 2: Estimation results for car use change for Beijing (multinomial logit model)

\begin{tabular}{|c|c|c|c|c|c|c|c|c|}
\hline & \multicolumn{4}{|c|}{ (1) Decrease km } & \multicolumn{4}{|c|}{ (2) Increase km } \\
\hline & \multicolumn{2}{|c|}{ Model 1} & \multicolumn{2}{|c|}{ Model 2} & \multicolumn{2}{|c|}{ Model 1} & \multicolumn{2}{|c|}{ Model 2} \\
\hline & Beta & Sig & Beta & Sig. & Beta & Sig. & Beta & Sig. \\
\hline Constant & -1.163 & 0.000 & -1.998 & 0.000 & -3.247 & 0.000 & -5.770 & 0.000 \\
\hline Male & 0.049 & 0.702 & 0.125 & 0.336 & -0.286 & 0.092 & -0.078 & 0.661 \\
\hline Income> $¥ 6,000$ & -0.471 & 0.000 & -0.464 & 0.001 & -1.004 & 0.000 & -0.981 & 0.000 \\
\hline $\begin{array}{l}\text { University edu- } \\
\text { cation }\end{array}$ & 0.332 & 0.031 & 0.385 & 0.014 & 0.995 & 0.000 & 0.967 & 0.000 \\
\hline $\begin{array}{l}\text { Household larg- } \\
\text { er than } 2 \text { persons }\end{array}$ & 1.019 & 0.000 & 1.030 & 0.000 & 1.174 & 0.000 & 1.175 & 0.000 \\
\hline $\begin{array}{l}\text { More than one } \\
\text { car }\end{array}$ & -0.139 & 0.529 & -0.113 & 0.618 & -0.079 & 0.788 & 0.111 & 0.721 \\
\hline $100-200 \mathrm{~km}$ & 0.264 & 0.100 & 0.186 & 0.255 & 0.232 & 0.305 & 0.087 & 0.710 \\
\hline$>200 \mathrm{~km}$ & 0.426 & 0.006 & 0.329 & 0.038 & 0.874 & 0.000 & 0.610 & 0.005 \\
\hline Credit price $¥ 0.8$ & 0.293 & 0.054 & 0.270 & 0.082 & 0.715 & 0.001 & 0.543 & 0.012 \\
\hline Credit price $¥ 1.0$ & 0.358 & 0.020 & 0.338 & 0.030 & 0.620 & 0.003 & 0.553 & 0.012 \\
\hline $\begin{array}{l}50 \text { credits sur- } \\
\text { plus }\end{array}$ & -0.184 & 0.142 & -0.172 & 0.176 & 0.714 & 0.000 & 0.763 & 0.000 \\
\hline $\begin{array}{l}\text { Instrumental car } \\
\text { use }\end{array}$ & & & 0.058 & 0.125 & & & 0.034 & 0.519 \\
\hline Symbolic car use & & & 0.224 & 0.000 & & & 0.446 & 0.000 \\
\hline Affective car use & & & -0.063 & 0.202 & & & 0.119 & 0.113 \\
\hline Log-likelihood & -12 & 824 & -12 & & & & & \\
\hline Adjusted $\mathrm{R}^{2}$ & & & & & & & & \\
\hline LR chisq & & & & & & & & \\
\hline p-value & & & & & & & & \\
\hline
\end{tabular}


Table 3: Estimation results for car use change for the Netherlands (binary logit model)

\begin{tabular}{|c|c|c|c|c|c|c|c|c|}
\hline & \multicolumn{2}{|c|}{ Model 1} & \multicolumn{2}{|c|}{ Model 2} & \multicolumn{2}{|c|}{ Model 3} & \multicolumn{2}{|c|}{ Model 4} \\
\hline & Beta & Sig. & Beta & Sig. & Beta & Sig. & Beta & Sig. \\
\hline Constant & -1.079 & 0.009 & -0.553 & 0.344 & -1.354 & 0.023 & -0.688 & 0.374 \\
\hline Male & -0.332 & 0.170 & -0.464 & 0.066 & 0.315 & 0.224 & -0.482 & 0.076 \\
\hline Income $>€ 2.500$ & -0.653 & 0.022 & -0.716 & 0.016 & -0.776 & 0.011 & -0.875 & 0.006 \\
\hline No income stated & -0.080 & 0.796 & -0.177 & 0.577 & -0.172 & 0.594 & -0.293 & 0.376 \\
\hline $\begin{array}{l}\text { HBO and University } \\
\text { education }\end{array}$ & 0.590 & 0.020 & 0.586 & 0.026 & 0.694 & 0.008 & 0.731 & 0.008 \\
\hline Presence of children & 0.032 & 0.898 & 0.038 & 0.884 & -0.120 & 0.664 & -0.132 & 0.646 \\
\hline More than one car & 0.065 & 0.802 & 0.010 & 0.970 & 0.009 & 0.974 & -0.089 & 0.756 \\
\hline $200-400 \mathrm{~km}$ & 0.548 & 0.060 & 0.670 & 0.027 & 0.578 & 0.052 & 0.711 & 0.021 \\
\hline$>400 \mathrm{~km}$ & 0.552 & 0.061 & 0.808 & 0.010 & 0.624 & 0.046 & 0.863 & 0.009 \\
\hline Credit price $€ 0.15$ & -0.200 & 0.501 & -0.133 & 0.663 & -0.177 & 0.556 & -0.112 & 0.719 \\
\hline Credit price $€ 0.20$ & -0.011 & 0.970 & 0.120 & 0.681 & -0.008 & 0.977 & 0.122 & 0.677 \\
\hline $15 \%$ credit shortage & 0.068 & 0.817 & 0.144 & 0.639 & 0.069 & 0.817 & 0.137 & 0.658 \\
\hline $15 \%$ credit surplus & -0.903 & 0.009 & -0.881 & 0.013 & -0.907 & 0.009 & -0.928 & 0.010 \\
\hline $30 \%$ credit surplus & -0.936 & 0.008 & -0.912 & 0.011 & -0.944 & 0.008 & -0.947 & 0.009 \\
\hline Instrumental car use & & & -0.233 & 0.001 & & & -0.255 & 0.000 \\
\hline Symbolic car use & & & -0.236 & 0.010 & & & -0.222 & 0.019 \\
\hline Affective car use & & & 0.192 & 0.021 & & & 0.214 & 0.012 \\
\hline Age $>45$ & & & & & 0.142 & 0.604 & 0.192 & 0.515 \\
\hline Couple & & & & & 0.553 & 0.115 & 0.583 & 0.108 \\
\hline Has paid work & & & & & -0.266 & 0.321 & -0.274 & 0.310 \\
\hline Partner has work & & & & & 0.107 & 0.722 & 0.029 & 0.925 \\
\hline Lives in urban area & & & & & -0.051 & 0.844 & -0.259 & 0.342 \\
\hline Log-likelihood & -229 & 393 & -218 & & -220 & 209 & -21 & 091 \\
\hline Adjusted $\mathrm{R}^{2}$ & & & & & & & & \\
\hline LR chisq & & & & & & & & \\
\hline p-value & 0.0 & & & & & & & \\
\hline
\end{tabular}

\subsubsection{Beijing}

Because behavioral change consists of two types of change in Beijing, driving more or driving less, we estimated a multinomial logit (MNL) model, which is a much-used discrete choice model. Here, three outcome alternatives are defined: reduce VKT, increase VKT or no-change (base outcome). Table 2 presents the estimation results of the model. We pooled the data of both the 50 credits shortage and 50 credits surplus to estimate the effect of the credit shortage/surplus (i.e., financial loss/gain) in one model. Two separate models have been estimated, with the second specification adding the three caruse attitudes. By estimating two separate models, we can detect the way in which car attitudes relate to socio-demographic characteristics.

A first observation is that many of the variables that have a significant effect have an effect in the same direction for both alternatives (decrease and increase VKT). Income has a significant effect on both change alternatives and suggests that car owners with higher incomes prefer to stick to the status quo. Those with lower incomes are more likely to decrease their car use, which is an expected outcome as 
those with lower incomes are widely regarded as being more price-sensitive and having a lower value of time (VoT) (Ubbels \& Verhoef, 2005; Rienstra, Rietveld, \& Verhoef, 1999). However, those with lower incomes are also more likely to report an increase in their VKT, which is counterintuitive and difficult to explain. It could be that lower income groups are more likely to travel by alternative modes at present, or they are less able to by-pass the current driving restrictions (by being more flexible, by being more willing to pay fees when breaking the rules, or by relying on other cars), and therefore they are more likely to foresee increased car use under TDC conditions. Another reason could be that the financial (dis)incentive is simply too small to find evidence for lower income households that are less prone to increase car use under higher costs.

Higher education has a significant and positive effect on both VKT decrease and increase, as has household size. Those with higher education and larger households might have a higher preferred car reliance (e.g., the presence of young children, larger commute distances), which possibly explains their VKT increase. However, at the same time, these groups also report a higher willingness to decrease their VKT. Other unmeasured, underlying characteristics and activity participation patterns (both temporally and spatially defined) might provide an explanation for these seemingly contradictory behaviors. With regard to VKT travelled, the group with the highest reported VKT $(200-400 \mathrm{~km})$ is more likely to change car use, again both in terms of VKT reduction and VKT increase. A high VKT might be an indication of a larger car reliance, which leads to a higher preference for increasing VKT under TDC, but at the same time, drivers with VKT generally make more trips, which leads to greater car use reduction potential. Again, other unmeasured factors might play a role in influencing the actual choice outcome.

The results show a price effect in that willingness to decrease VKT is greater for those who face a higher per kilometer price ( $¥ 0.8$ and $¥ 1.0$ ). Strikingly, those who are assigned a higher credit price also report being more likely to increase VKT. This appears to be at odds with economic theory, and additional research is needed to determine whether this finding could be corroborated, preferably with higher price levels. When comparing the shortage and surplus scenarios, a higher willingness to increase VKT is found in the case of the surplus scenario, which is not surprising given that increasing car use would not imply additional costs of up to 50 additional kilometers in this scenario. In the surplus scenario, the effect of decreasing VKT is negative; however, this effect is not significant, which means that there is no systematic difference between the car reduction preferences under the shortage and surplus scenarios.

The inclusion of the car attitude variables leads to only very minor changes in the socio-demographic effects. Whereas males tend to be less likely to increase car use than females (only significant at the $10 \%$ level), this effect disappears with the inclusion of car attitudes, which suggests that the small gender difference can be explained by these attitudes. With regard to the attitudes themselves, only symbolic car attachment is found to have an effect on willingness to change. It has both a positive effect on decreasing and increasing VKT, although the effect is larger for increasing VKT. Whereas increasing VKT might be explained by those with higher symbolic car attachment being more eager to use their cars if possible, these people might also be those with higher levels of not strictly necessary car use, which creates opportunities for car use reduction. Of course, all the possible explanations for the observed stated behaviors are only put forward in a tentative way and clearly call for further research to shed light on the relevant underlying explanatory mechanisms and preferences.

\subsubsection{The Netherlands}

For the Dutch data, we estimated a binary logit regression model because the low frequency of cases of reported car use increase (8 out of 106 cases of change) prevents the estimation of an MNL model, which is similar to the Beijing case. The choice alternatives for the Dutch data are therefore change (i.e., 
reduce VKT in most cases) and no-change (base outcome). Table 3 presents the estimation results of four different models. The first two models include the variables for which we also have information in the Beijing context and that hence enable direct comparison. The third and the fourth models include the personal characteristics for which we only have information from the Dutch respondents.

Having a higher income has a negative effect on willingness to change, whereas a higher education positively affects the likelihood of changing car use. As mentioned above in the Beijing case, people with higher incomes are generally believed to have a lower marginal utility of money and therefore to have a lower preparedness to change behavior to circumvent losses or increase gains. The higher willingness to change among higher educated people might relate to such people often working in larger cities, where alternative travel modes are better provided, and generally being more flexible in choosing their working time and location.

Driving more kilometers leads to a higher preparedness to change car use, which is an effect that is stronger when car attitudes have been controlled for. Note that in the Dutch case, VKT acts as a proxy for total financial loss or gain in the scenario, as the credit budget is a function of VKT, and thus people who drive more kilometers not only have more car reduction potential but also face larger losses or gains. At the same time, the size of the financial outcome is also determined by the respondent being assigned either a $15 \%$ or a $30 \%$ credit shortage/surplus rule; however, there is no significant difference between these two credit availability percentages in both the shortage and surplus scenarios. As expected, whether the scenario implies a loss or a gain does have an effect, as the surplus scenarios significantly differ from the $30 \%$ shortage scenario. Marginal price (credit price level) does not have an effect, which is similar to the findings of Dogterom et al. (2018), using the same price levels.

In contrast to the Beijing results, the car attitudes all have a significant effect. Those with a higher instrumental car attachment are less likely to adapt their car travel, as are those with a higher symbolic car attachment, both of which are expected results. However, those who derive more pleasure from driving are more willing to change. It could be that these people make more leisure- and/or recreational trips, which are trips that could potentially be changed more easily when confronted with a road pricing measure. Controlling for car attitudes does result in the gender variable gaining a significant effect, with males being more likely to prefer the no-change option, which leads to stronger effects for VKT. Overall, the inclusion of car attitudes does not change the level of significance nor the sign of the coefficients of the variables that have an effect in model 1. Further, the inclusion of the additional personal characteristics in models 3 and 4 does not alter the effects. None of these characteristics are found to have a significant effect on willingness to change and together lead only to a small increase in model fit.

\subsubsection{Synthesis Beijing - The Netherlands}

When we compare the statistical results from Beijing and the Netherlands, a first observation is that the explanatory power of the models, which is indicated by the adjusted $\mathrm{R}^{2}$, is very similar for both contexts. Although the explanatory power is very modest, the similar magnitudes suggest a "general" relative importance of the included socio-demographic and attitudinal characteristics in explaining car users' willingness to change under TDC in both contexts.

In terms of the personal characteristics that are found to influence willingness to change, we found a similar income, education and car-use intensity effect. The car owners with a higher education and higher reported VKT tend to change car use more often, whereas those with a higher income are less likely to adapt their car use in response to the measure. The income effect can be well explained by the lower marginal value of money of higher income households that therefore are less sensitive to an increase in loss or gain that is faced under the measure. This income effect is also found in the wider road pricing literature (Kockelman \& Kalmanje, 2005; Ubbels \& Verhoef, 2005; Washbrook, Haider, 
\& Jaccard, 2006; Rienstra et al., 1999). However, when Dogterom et al. (2018), using three income levels, found an income effect, they only found middle income households to report a significantly higher willingness to change. The education effect is an effect that has not previously been reported in the very limited strand of literature on TDC behaviors. A positive impact of the presence of children on willingness to change that is reported by Dogterom et al. (2018) and other studies on road pricing (Ubbels, 2006; Gehlert, Kramer, Nielsen, \& Schlag, 2011; Zanni et al., 2013) could only be found for the Beijing case (where we interpreted children to be present in households that are larger than 2 persons).

With regard to the TDC scenario characteristics we found some differences between Beijing and the Netherlands. The Dutch respondents indicated a significantly stronger preference for changing car use under a credit shortage situation compared to a surplus situation, which was also reported by Dogterom et al. (2018) and Zanni, et al. (2013). In the Beijing context, a stronger preference for reducing car use in the shortage scenario could not be found, but instead there was a stronger preference for increasing car use in the surplus scenario. Credit price had an effect in Beijing, where each participant received the same amount of credits, with a higher credit price leading to larger preparedness to change; however, in the Netherlands, where financial outcome was a function of both credit price and VKT, an effect of credit price per se could not be found. The differences in the way in which credit budgets and financial outcome were defined might have played a role in these different outcomes.

In addition, regarding car attitudes, we found some contrasting results. Whereas the respondents' subjective evaluation of their instrumental, symbolic and affective car use all had an effect for the Dutch respondents, only symbolic car use had an effect in Beijing. Additionally, whereas a higher symbolic car use had a negative effect on willingness to change in the Netherlands, in Beijing it had a positive effect, which is in contrast with our expectations given the high symbolic meaning of car ownership and use in contemporary China; although, at the same time, the effect of symbolic car attachment was larger for an increase of car use than for a reduction of car use.

A striking result is that the factors that were found to affect willingness to change for Beijing car owners do have an effect of the same direction on both reported VKT decrease and increase. This is difficult to explain in some cases, and we attempted to provide some possible explanations in the subsection on the Beijing results; however, further and more detailed research on these identified preferences is clearly needed.

\section{$5 \quad$ Conclusion and discussion}

At present, there is a lively strand of literature that theoretically explores the potential of tradable driving credits (TDC) and that considers it to be a promising alternative to road pricing and driving restrictions, which generally face significant public aversion and have demonstrated the production of considerable negative side effects. However, individual-based empirical research into drivers' responses to the measure is scarce and even lacking for the Chinese context. In this paper, we therefore investigated car owners' willingness to change under a hypothetical TDC measure in Beijing (China) and the Netherlands. By means of a direct comparison between both contexts, this research addressed the research questions of how drivers in these different contexts respond to the measure and to what extent preferences of drivers in an Asian megacity are similar or different to what has been found in a European context.

We found substantial differences in the percentages of car owners who are willing to adapt their car use if a distance-based TDC scenario, in which people would receive credits below or above their reported travel demand by distance $(\mathrm{km})$, would apply. Nearly $60 \%$ of the Beijing car owners indicated a willingness to change, whereas in the Netherlands this was slightly more than $20 \%$. For the Dutch data, the indicated willingness to change substantially differs from the rate that was found by Dogterom 
et al. (2018) based on other Dutch data. They found also a willingness of approximately $60 \%$, however, in their experiment more of the respondents faced a loss, and only frequent car commuters, who potentially have more options for changing travel patterns, participated.

The ease with which car travel can be substituted in Beijing, which has good public transport facilities, might provide an explanation for the large difference in the likelihood of adapting car use between Beijing and the Netherlands. However, at the same time, a substantial part of the Beijing car owners reported an increased car use rather than a car use reduction $(21 \%$ and $38 \%$ of those who would change in the credit shortage and surplus scenarios, respectively), whereas in the Netherlands only a few car owners stated a willingness to increase their car use under TDC. It is possible that the Beijing drivers would expect TDC to replace the current one-day-no-driving restriction and expect better traffic conditions due to the absolute cap on traffic and therefore foresee their demand for car travel — currently suppressed — to increase despite the additional credit costs involved.

As such, the results show that TDC, especially in the context of Beijing, would not necessarily lead to a net reduction in congestion if a TDC scheme would work on the basis of fixed credit prices. Such a scheme would basically resemble a tax program, with the distinction that people who drive below a threshold can face a "reversed tax," i.e., receive a monetary reward. The participants would then "trade" with the regulator that has chosen to use predetermined prices to keep the scheme simple and understandable. In such a setting the regulators would require a priori information about the demand functions of the credits to guarantee a certain total VKT outcome, which is difficult in real life. However, in a true tradable credit scheme as it is typically understood in the literature, the regulator would set a cap on the total VKT and would let a dynamic market determine the credit price. As such, a TDC scheme is able to guarantee a certain outcome and therefore effectively reduce congestion, based on the VKT cap that is defined.

We therefore suggest that future research investigate car use preferences in such a dynamic setting. Investigating driver's responses in such a setting would not only be needed to obtain a more realistic appreciation of credit use and trading patterns, but it would also be needed to evaluate the impacts of credit price on different groups of drivers from an equity perspective. This is relevant, as many of the Beijing respondents, when they could leave a personal remark at the end of the experiment, expressed a concern that higher income drivers would simply buy all of the credits, which would drive up the credit price.

We used multinomial logit (MNL) (Beijing) and binary logit (Netherlands) regression models to estimate the effect of respondent and scenario characteristics on willingness to change. A limitation is that we had to rely on two different types of models to address the type of data that was available for both contexts. In contrast to the Dutch case, we pooled the data for the Beijing case to estimate the unique effect of either facing a shortage or a surplus scenario. Because the Beijing respondents were presented with both scenarios, the Beijing data are structured as repeated observations, which is a limitation because it might violate the assumptions that underlie MNL.

The modelling results showed that in both Beijing and the Netherlands willingness to change car use under TDC is higher for those with higher education and car use intensity, but lower for those with higher income. With regard to scenario effects and car attitudes our results are mixed, which might be partly explained by the differences in scenario design. The inclusion of the car attitudes did not fundamentally change the effects of the socio-demographic characteristics and did not much improve the model results. It could be that attitudes towards the TDC measure itself, attitudes towards car travel alternatives or a measure of a more concrete car use flexibility in relation to the trips that were reported in the experiment, could have functioned as more important explanatory factors for willingness to change under TDC. 
For Beijing, a remarkable observation is that many variables that have a significant effect on willingness to decrease car use also have a same-direction effect on willingness to increase car use. Whereas this indicates that some groups prefer the status quo, it is sometimes difficult to provide reasons why the same groups would show both more car use reduction and intensification behaviors. We provided some initial thoughts on possible explanations; however, this result clearly calls for further research. This future research on TDC responses in China should include a richer set of respondent characteristics, as our data omitted important characteristics such as age, type of work and residential and work location. Further, future research should seek to explicitly link behavioral responses to more detailed activity/trip patterns and access to competitive travel modes, as explanations might be found in these domains. A valuable next step would also be to appreciate the type of behavioral change in more detail, considering the size of change in kilometers and choice of travel alternatives.

The TDC scheme investigated in this study was straightforward, as we defined a scheme in which respondents needed credits for each kilometer they drove, irrespective of time and location. Of course, from a theoretical perspective, differentiation in time, location, car characteristics, etc., is likely to be desired to mitigate congestion and car-based pollution. At the same time, from an acceptability perspective, it is important that a TDC scheme is understandable, considered fair and lead to situation in which credit availability and credit price are predictable to a certain extent. More research is needed to find a good balance. Additionally, in terms of potential implementation, many practical and institutional conditions should be defined in more detail, for example with to the transferability of credits (e.g., Would credits be allowed to be transferred freely among family members?), trading (e.g., Direct trading with other drivers or indirect trading via third parties? Would banking be allowed), enforcement (e.g., How to monitor the system? What are the penalties for non-compliance?) and exceptions (e.g., Would visitors need to acquire credits?). It is likely that such design details will affect the performance of and behavioral reactions to the possible TDC schemes to a significant degree. Therefore, the effects should be examined more thoroughly, to which not only stated preference research as used in this study, but also pilot studies and simulations techniques could valuably contribute.

\section{Acknowledgments}

This research was funded by the Netherlands Organization for Scientific Research (NWO) (grant no. 435-12-212) and the National Natural Science Foundation of China (NSCF) (grant no. 71361130016), through their joint research program The Application of Operations Research in Urban Transport. The comments of the two anonymous reviewers are greatly appreciated. 


\section{References}

Bao, Y., Gao, Z., Xu, M., \& Yang, H. (2014). Tradable credit scheme for mobility management considering travelers' loss aversion. Transportation Research Part E, 68, 138-154. doi: 10.1016/j. tre.2014.05.007

Buitelaar, E., van der Heijden, R., \& Argiolu, R. (2007). Managing traffic by privatization of road capacity: A property rights approach. Transport Reviews, 27,699-713. doi: 10.1080/01441640701262949

Chen, X., \& Zhao, J. (2013). Bidding to drive: Car license auction policy in Shanghai and its public acceptance. Transport Policy, 27, 39-52. doi: 10.1016/j.tranpol.2012.11.016

Dales, J. H. (1968). Pollution, property and prices: An essay in policy-making and economics. Toronto: Toronto University Press.

Dogterom, N., Ettema, D., \& Dijst, M. (2018). Behavioral effects of a tradable driving credit scheme: Results of an online stated adaptation experiment in the Netherlands. Transportation Research Part $A$, 107, 52-64. doi: 10.1016/j.tra.2017.11.004

Dogterom, N., Ettema, D., \& Dijst, M. (2017). Tradable credits for managing car travel: A review of empirical research and relevant behavioral approaches. Transport Reviews, 37, 322-343. doi: 10.1080/01441647.2016.1245219

Fan, W., \& Jiang, X. (2013). Tradable mobility permits in roadway capacity allocation: Review and appraisal. Transport Policy, 30, 132-142. doi:10.1016/j.tranpol.2013.09.002

Gehlert, T., Kramer, C., Nielsen, O. A., \& Schlag, B. (2011). Socioeconomic differences in public acceptability and car use adaptation towards urban road pricing. Transport Policy, 18, 685-694. doi: 10.1016/j.tranpol.2011.01.003

Goddard, H. C. (1997). Using tradeable permits to achieve sustainability in the world's large cities. Environmental and Resource Economics, 10, 63-99.

Grant-Muller, S., \& Xu, M. (2014). The role of tradable credit schemes in road traffic congestion management. Transport Reviews, 34, 128-149. doi: 10.1080/01441647.2014.880754

Hao, H., Wang, H., \& Ouyang, M. (2011). Comparison of policies on vehicle ownership and use between Beijing and Shanghai and their impacts on fuel consumption by passenger vehicles. Energy Policy, 39, 1016-1021. doi: 10.1016/j.enpol.2010.11.039

Kockelman, K. M., \& Kalmanje, S. (2005). Credit-based congestion pricing: A policy proposal and the public's response. Transportation Research Part A, 39, 671-690. doi: 10.1016/j.tra.2005.02.014

Ng, W.-S., Schipper, L., \& Chen, Y. (2010). China motorization trends: New directions for crowded cities. Journal of Transport and Land Use, 3, 5-25. doi: 10.5198/jtlu.v3i3.151

Nie, Y. (2017). Why is license plate rationing not a good transport policy? Transportmetrica A: Transport Science, 9935, 1-23. doi: 10.1080/23249935.2016.1202354

Nie, Y. M., \& Yin, Y. (2013). Managing rush hour travel choices with tradable credit scheme. Transportation Research Part B, 50, 1-19. doi: 10.1016/j.trb.2013.01.00

Raux, C. (2004). The use of transferable permits in transport policy. Transportation Research Part D, 9 , 185-197. doi: 10.1016/j.trd.2004.01.001

Raux, C., Croissant, Y., \& Pons, D. (2015). Would personal carbon trading reduce travel emissions more effectively than a carbon tax? Transportation Research Part D, 35, 72-83. doi: 10.1016/j. $\operatorname{trd} .2014 .11 .008$

Rienstra, S. A., Rietveld, P., \& Verhoef, E. T. (1999). The social support for policy measures in passenger transport. A statistical analysis for the Netherlands. Transportation Research Part D, 4, 181-200. doi: 10.1016/S1361-9209(99)00005-X

Steg, L. (2005). Car use: lust and must. Instrumental, symbolic and affective motives for car use. Trans- 
portation Research Part A, 39, 147-162. doi: 10.1016/j.tra.2004.07.001

Sun, C., Zheng, S., \& Wang, R. (2014). Restricting driving for better traffic and clearer skies: Did it work in Beijing? Transport Policy, 32, 34-41. doi: 10.1016/j.tranpol.2013.12.010

Tietenberg, T. (2003). The tradable permits approach to protecting the commons: lessons for climate change. Oxford Review of Economic Policy, 19, 400-419.

Ubbels, B. (2006). Road pricing. Effectiveness, acceptance and institutional aspects. PhD thesis, Faculteit der Economische Wetenschappen en Bedrijfskunde, Free University, Amsterdam, the Netherlands.

Ubbels, B., \& Verhoef, E. (2005). Behavioral responses to road pricing. Empirical results from a survey among Dutch car owners. European Transport, 31, 101-117.

Verhoef, E. T., Nijkamp, P., \& Rietveld, P. (1997). Tradeable permits: Their potential in the regulation of road transport externalities. Environment and Planning B, 24, 527-548.

Viegas, J. (2001). Making urban road pricing acceptable and effective: Searching for quality and equity in urban mobility. Transport Policy, 8, 289-294. doi: 10.1016/S0967-070X(01)00024-5.

Wang, G., Gao, Z., Xu., M., \& Sun, H. (2014). Models and a relaxation algorithm for continuous network design problem with a tradable credit scheme and equity constraints. Computers and Operations Research, 41, 252-261. doi: 10.1016/j.cor.2012.11.010

Wang, L., Xu, J., \& Qin, P. (2014). Will a driving restriction policy reduce car trips? The case study of Beijing, China. Transportation Research Part A, 67, 279-290. doi: 10.1016/j.tra.2014.07.014

Wang, X., Yang, H., Zhu, D., \& Li, C. (2012). Tradable travel credits for congestion management with heterogeneous users. Transportation Research Part E, 48, 426-437. doi: 10.1016/j.tre.2011.10.007

Wang, Z., \& Liu, W. (2015). Determinants of CO2 emissions from household daily travel in Beijing, China: Individual travel characteristic perspectives. Applied Energy, 158, 292-299. doi: 10.1016/j. apenergy.2015.08.065

Washbrook, K., Haider, W., \& Jaccard, M. (2006). Estimating commuter mode choice: A discrete choice analysis of the impact of road pricing and parking charges. Transportation, 33, 621-639.

Williams, M., \&Arkaraprasertkul, N. (2016). Mobilityin aglobal city: Makingsense ofShanghai's growing automobile-dominated transport culture. Urban Studies, 1-16. doi: 10.1177/0042098016637568

Wu, D., Yin, Y., Lawphongpanich, S., \& Yang, H. (2012). Design of more equitable congestion pricing and tradable credit schemes for multimodal transportation networks. Transportation Research Part B, 46, 1273-1287. doi: 10.1016/j.trb.2012.05.004

Xiao, F., Qian, Z., \& Zhang, H. M. (2013). Managing bottleneck congestion with tradable credits. Transportation Research Part B, 56, 1-14. doi: 10.1016/j.trb.2013.06.016

Xu, M., Grant-Muller, S., Huang, H.-J., \& Gao, Z. (2015). Transport management measures in the post-Olympic Games period: Supporting sustainable urban mobility for Beijing? International Journal of Sustainable Development and World Ecology, 22, 1-14. doi: 10.1080/13504509.2014.990542

Xu, M., \& Grant-Muller, S. (2016a). Trip mode and travel pattern impacts of a tradable credits scheme: A case study of Beijing. Transport Policy, 47, 72-83. doi: 10.1016/j.tranpol.2015.12.00

Xu, M., \& Grant-Muller, S. (2016b). VMT reduction and potential environmental effects with a tradable credits scheme: A simulation case study of Great Britain. International Journal of Sustainable Development and World Ecology, 23, 1-12. doi: 10.1080/13504509.2016.1165756

Yang, H., \& Wang, X. (2011). Managing network mobility with tradable credits. Transportation Research Part B, 45, 580-594. doi: 10.1016/j.trb.2010.10.002

Yang, J., Liu, Y., Qin, P., \& Liu, A. A. (2014). A review of Beijing's vehicle registration lottery: Shortterm effects on vehicle growth and fuel consumption. Energy Policy, 75, 157-166. doi: 10.1016/j. enpol.2014.05.055 
Ye, H., \& Yang, H. (2013). Continuous price and flow dynamics of tradable mobility credits. Transportation Research Part B, 57, 436-450. doi: 10.1016/j.trb.2013.05.007

Zanni, A. M., Bristow, A. L., \& Wardman, M. (2013). The potential behavioral effect of personal carbon trading: Results from an experimental survey. Journal of Environmental Economics and Policy, 2, 222-243. 